\title{
Foveal Exudative Macroaneurysm Treated with Intravitreal Ranibizumab
}

\author{
Carlos Menezes Rui Carvalho Carla Teixeira José Alberto Lemos \\ Rita Gonçalves Pedro Coelho André Lima
}

Department of Ophthalmology, Pedro Hispano Hospital, Matosinhos, Portugal

\section{Key Words}

Exudative retinal macroaneurysm · Fovea $\cdot$ Intravitreal ranibizumab

\begin{abstract}
Purpose: We report a case of a foveal macroaneurysm with long-standing macular edema in a rare location, successfully treated with intravitreal ranibizumab. Methods: We report the case of a 52-year-old man with left eye long-term visual loss due to macular edema caused by a retinal macroaneurysm, localized about $400 \mu \mathrm{m}$ from the center of the fovea, and its response to 6 monthly ranibizumab intravitreal injections. His best-corrected visual acuity and morphological data evaluated by optical coherence tomography and fluorescein angiography are presented. Results: His best-corrected visual acuity improved from 1/10 to 3/10 after the 3rd injection, and from $1 / 10$ to $4 / 10$ after the 6 th one. The central retinal thickness was evaluated by optical coherence tomography and improved from 310 to $233 \mu \mathrm{m}$, with the resolution of both the associated serous detachments and the cystoid macular edema; an almost complete reabsorption of the hard exudates at the end of the treatment was also observed. The macroaneurysm lumen almost obliterated after the 3rd injection and completely collapsed at the end of treatment. Conclusions: Intravitreal ranibizumab may be effective in the treatment of long-standing macular edema associated with foveal macroaneurysms. To the best of our knowledge, this is the first report of a retinal macroaneurysm located so close to the foveal avascular zone.


Menezes et al.: Foveal Exudative Macroaneurysm Treated with Intravitreal Ranibizumab

\section{Introduction}

Retinal macroaneurysms are uncommon focal dilations of the arterial wall that usually arise upstream the first 3 bifurcations of the temporal branches of the central retinal artery $[1,2]$. They are associated with aging, female gender and systemic vascular pathology, most often hypertension, but also dyslipidemia and atherosclerosis [1, 2]. They can be morphologically divided into saccular or fusiform and functionally, depending on the state of the bloodretinal barrier, into exudative, hemorrhagic or quiescent $[1,2]$.

Although the majority has a benign course with spontaneous involution, foveal commitment by bleeding and chronic macular edema are major causes of irreversible vision loss $[1,2]$.

There is no established treatment protocol [1, 2]. In exudative macroaneurysms with foveal commitment, the most popular treatment modality is laser photocoagulation directed towards the lesion or the surrounding tissue [3]. Treatment with intravitreal vascular endothelium growth factor (VEGF) inhibitors (bevacizumab [4-9] and ranibizumab [8, 10, 11]) has had a few encouraging outcomes.

We present a rare case of a long-standing exudative retinal macroaneurysm, unsuitable for laser photocoagulation due to its foveal location, which was successfully treated with intravitreal ranibizumab.

\section{Case Presentation}

A 52-year-old man presented with vision loss and metamorphopsia in his OS (left eye) for at least 3 years. His past ophthalmological history was positive for a foveal exudative macroaneurysm in his OS, documented in a fluorescein angiogram (FA) 2 years before. He was rescheduled for an observation, but lost to follow-up. His medical history was positive for well-controlled type 2 diabetes with a 5-year duration as well as hypertension diagnosed 2 years earlier. His baseline blood pressure was 170/90 and 140/90 mm Hg in his last medical consultation. The lipid profile was within normal limits.

His best-corrected visual acuity (BCVA) was 10/10 in his OD (right eye) and 1/10 in his OS. Slit-lamp biomicroscopy was unremarkable and intraocular pressures were $19 \mathrm{~mm} \mathrm{Hg}$ bilaterally. Fundoscopy revealed a bilateral mild diabetic retinopathy and, in his OS, a yellowish round foveal lesion surrounded by macular edema and hard exudates (fig. 1a, b). FA showed typical features of a saccular arterial macroaneurysm, namely homogeneity and almost total filling in the middle phase and late diffusion (fig. 1c, d). Optical coherence tomography (Copernicus S-OCT) confirmed the diagnosis, showing a tubular structure, with a hyperreflective wall and a hyporeflective lumen, with a diameter of about $250 \mu \mathrm{m}$ and lying in the inner retina about $400 \mu \mathrm{m}$ nasally from the center of the fovea. Cystoid macular edema, hard exudates and a foveal neurosensory detachment were present with a central retinal thickness of $310 \mu \mathrm{m}$ (fig. 1e).

Due to the location of the macroaneurysm, direct laser treatment was contraindicated. After obtaining the written consent for the off-label use of intravitreal ranibizumab, the patient was scheduled for 3 monthly doses $(0.5 \mathrm{mg}$ in $0.05 \mathrm{ml})$ in his $0 S$.

After the third injection, his BCVA improved to $3 / 10$, the metamorphopsia decreased, and the macroaneurysm showed features of regression, namely an irregular and incomplete filling with less diffusion in FA (fig. 2a) and an almost complete occlusion of the macroaneurysm lumen with a resolution of the neurosensory detachment in the OCT (fig. 2b). Due to an 
Menezes et al.: Foveal Exudative Macroaneurysm Treated with Intravitreal Ranibizumab

incomplete closure and persistent macular edema, the patient was referred for additional monthly injections of intravitreal ranibizumab.

After the 6th injection, the BCVA improved to 4/10, the metamorphopsia disappeared, and the macroaneurysm resolved, as shown both in FA (fig. 2c) and in OCT (fig. 2d), with a resolution of the macular edema (central retinal thickness of $233 \mu \mathrm{m}$ ) and less hard exudates.

The patient remains stable 5 months later (fig. 3). No adverse effects occurred in the context of anti-VEGF therapy.

\section{Discussion}

Retinal macroaneurysms usually occur within the first 3 bifurcations of the central retinal artery $[1,2]$ and most often have a benign course with gradual thrombosis, fibrosis and involution $[1,2]$. The macroaneurysm described in this case has typical features both in OCT [12] and FA [2], but it is not in concordance with the well-established clinical and anatomical features. First of all, the proximity of the macroaneurysm to the center of the fovea, so close to the foveal avascular zone, seems to indicate an origin in the terminal arteriolar retinal network. This rare location is, to the best of our knowledge, the closest location of a retinal macroaneurysm to the foveal center ever described. On the other hand, the long-standing visual loss and the same angiographic pattern presented 2 years before seem to indicate a chronic and stable evolution. We hypothesize that the lower pressure of the smaller branches of the retinal arterial vasculature may explain not only the purely exudative behavior, but also the chronicity of this macroaneurysm that did not regress even after controlling hypertension for 2 years [2].

Exudative retinal macroaneurysms impair vision when the fovea is committed by macular edema, serous retinal detachment or hard exudates [3]. These situations are usually considered indications to treat retinal macroaneurysms instead of observing and waiting for them to regress spontaneously. Since laser photocoagulation was contraindicated due to the foveal location, we referred the patient for monthly intravitreal injections of ranibizumab. Despite being off-label, both VEGF inhibitors, ranibizumab $[8,10,11]$ and mainly bevacizumab [4-9], have been successfully used in the treatment of exudative retinal macroaneurysms threatening the fovea.

Partial regression of the macroaneurysm was obtained with the resolution of the serous detachment after the 3rd intravitreal injection of ranibizumab and the complete closure and normalization of the central retina thickness, apart from some residual exudates (after the 6 th one). The functional outcome was good with vision improvement from $1 / 10$ to $4 / 10$ and metamorphopsia resolution. Despite good, this improvement was limited by the chronicity of the macular edema and the associated microstructural damage to the photoreceptors and retina cells.

The majority of the reported cases in the literature achieve macroaneurysm and macular edema regression after 2 or 3 intravitreal injections of bevacizumab [4-9] or ranibizumab $[8,10,11]$. The chronicity of this case may explain the partial occlusion after 3 injections and the need for more injections to achieve a complete regression and resolution of macular edema.

As a conclusion, intravitreal ranibizumab may be effective in the treatment of macular edema associated with exudative macroaneurysms, even if long-standing and foveal. The VEGF-associated increased permeability and dilatation of the arterial wall inhibition seems to be the key to success of anti-VEGF therapy in macroaneurysm regression [7]. 
Menezes et al.: Foveal Exudative Macroaneurysm Treated with Intravitreal Ranibizumab

\section{Acknowledgment}

The authors thank Dr. Ana Duarte, Orthotic Technician (Department of Ophthalmology, Pedro Hispano Hospital, Matosinhos, Portugal), for her important contribution in the acquisition of data for the work.

\section{Statement of Ethics}

The authors state that the patient gave his informed consent both to the off-label use of ranibizumab and to the publication of this case report. The authors also state that this publication was conducted in accordance to the tenets of Helsinki and approved by our committee on human research.

\section{Disclosure Statement}

None of the authors has conflicts of interest, and no financial support was received for this paper.

\section{References}

1 Pitkanen L, Tomilla P, Kaaniranta K, JaasKlainen JE, Kinnunen K: Retinal arterial macroaneurysms. Acta Ophthalmol 2014;92:101-104.

-2 Moosavi RA, Fong KC, Chopdar A: Retinal artery macroaneurysms: clinical and fluorescein angiographic features in 34 patients. Eye (Lond) 2006;20:1011-1020.

-3 Meyer JC, Ahmad BU, Blinder KJ, Shah GK: Laser therapy versus observation for symptomatic retinal artery macroaneurysms. Graefes Arch Clin Exp Ophthalmol 2015;253:537-541.

4 Chanana B, Azad RV: Intravitreal bevacizumab for macular edema secondary to retinal macroaneurysm. Eye 2009;23:491-493.

5 Jonas JB, Schmid-Bauer M: Intravitreal bevacizumab for retinal macroaneurysm. Acta Ophthalmol 2010;88:e284.

6 Golan S, Goldenberg D, Goldstein M: Long-term follow-up of intravitreal bevacizumab in retinal arterial macroaneurysm: a case report. Case Rep Ophthalmol 2011;2:387-391.

7 Pichi F, Morara M, Torraza C, Manzi G, Alkabes M, Balducci N, et al: Intravitreal bevacizumab for macular complications from retinal arterial macroaneurysms. Am J Ophthalmol 2013;155:287-294.

-8 Zweifel SA, Tönz MS, Pfenninger L, Becker M, Michels S: Intravitreal anti-VEGF therapy for retinal macroaneurysm. Klin Monbl Augenheilkd 2013;230:392-395.

$\checkmark 9$ Auimiller MS, Rinehart J: Multi-layered haemorrhage secondary to retinal arterial macroaneurysm: a case report and review. Clin Exp Optom 2015;98:117-21.

$\checkmark 10$ Wenkstern AR, Petersen H: Intravitreal ranibizumab in retinal macroaneurysm. Graefes Arch Clin Ophthalmol 2010;248:1667-1670.

11 Gallego-Pinazo R, Martinez-Castillo S, Arévalo JF, Diaz-Llopis M: Ranibizumab for retinal arterial macroaneurysm. Graefes Arch Clin Exp Ophthalmol 2011;249:1267-1268.

-12 Goldenberg D, Soiberman U, Loewenstein A, Goldstein M: Heidelberg spectral-domain optical coherence tomographic findings in retinal artery macroaneurysm. Retina 2012;32:990-995.

This case was presented as a poster at the 57th Congress of the Portuguese Society of Ophthalmology in December 2014, although only with a partial outcome. 
Menezes et al.: Foveal Exudative Macroaneurysm Treated with Intravitreal Ranibizumab
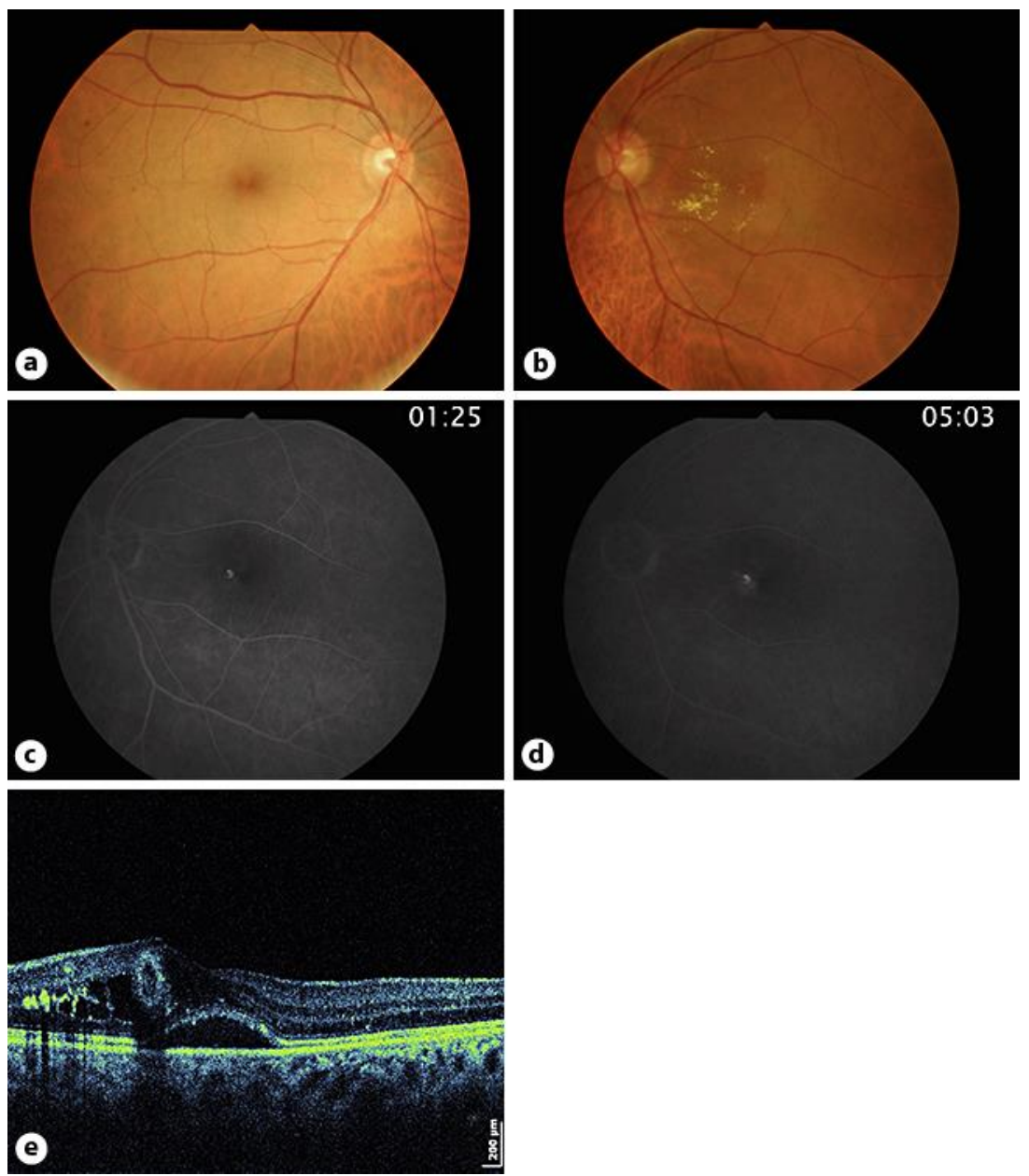

Fig. 1. a, b Fundus retinography showing bilateral mild retinopathy (microaneurysms) and a retinal macroaneurysm in the nasal fovea of the OS with macular edema and surrounding hard exudates. c, $\mathbf{d}$ FA of the OS showing homogenous and almost a total filling of the macroaneurysm in the middle phase and late diffusion. e OCT (Copernicus S-OCT) of the OS showing the macroaneurysm as a structure with a hypereflective wall and a hyporeflective lumen, lying in the inner retina around $400 \mu \mathrm{m}$ nasally to the foveal center and surrounded by cystoid macular edema, hard exudates and a foveal neurosensory detachment. 


\section{Case Reports in \\ Ophthalmology}

\begin{tabular}{l|l}
\hline \multicolumn{2}{l}{ Case Rep Ophthalmol 2015;6:170-175 } \\
\hline DOI: 10.1159/000431353 & $\begin{array}{l}\text { @ 2015 S. Karger AG, Basel } \\
\text { www.karger.com/cop }\end{array}$ \\
\hline
\end{tabular}

Menezes et al.: Foveal Exudative Macroaneurysm Treated with Intravitreal Ranibizumab
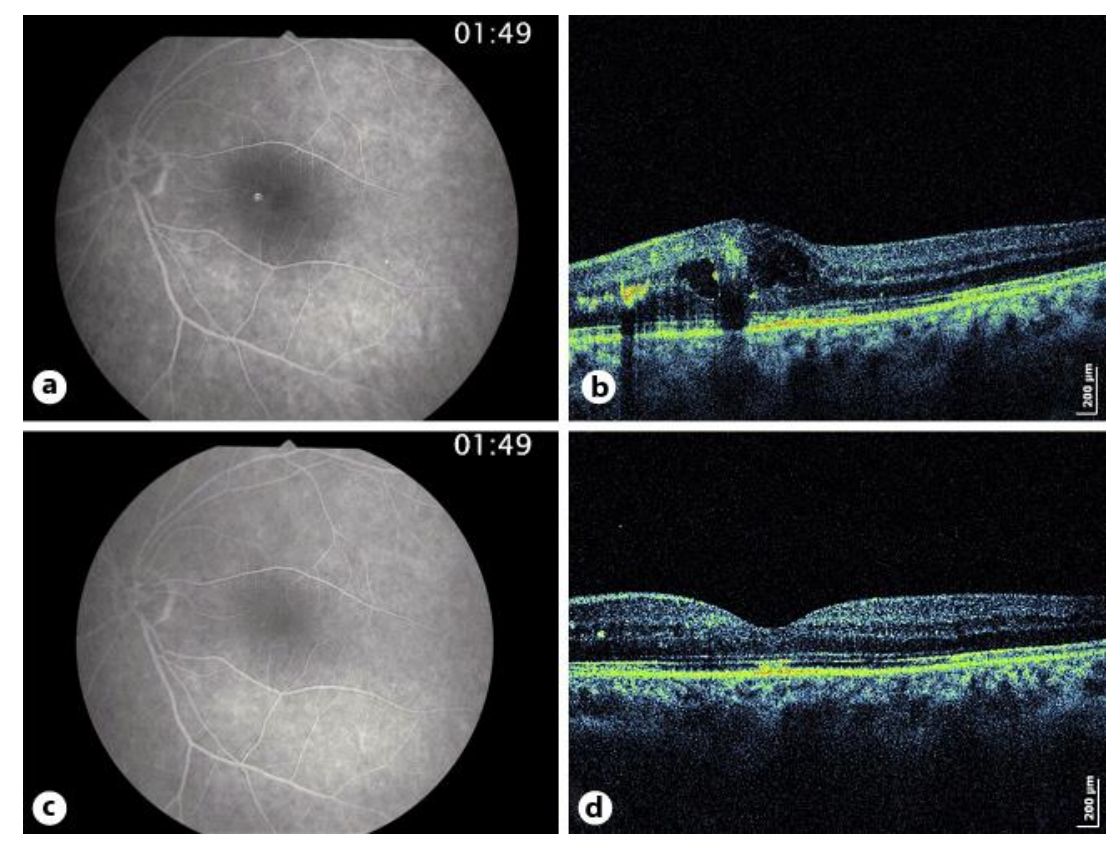

Fig. 2. a A middle-phase angiogram of the OS after the 3rd injection of intravitreal ranibizumab showing an irregular and incomplete filling of the macroaneurysm and less diffusion. $\mathbf{b}$ OCT (Copernicus S-OCT) of the OS after the 3rd injection of intravitreal ranibizumab showing an almost complete occlusion of the macroaneurysm lumen represented by an almost complete hyperreflective tubular structure and the resolution of the neurosensory detachment. c A middle-phase angiogram of the OS after the 6th injection of intravitreal ranibizumab showing a full regression of the macroaneurysm. $d$ OCT (Copernicus S-OCT) of the OS after the 6th injection of intravitreal ranibizumab showing the macroaneurysm as a shrunken hypereflective structure, resolution of the cystoid macular edema and only a few residual hard exudates.

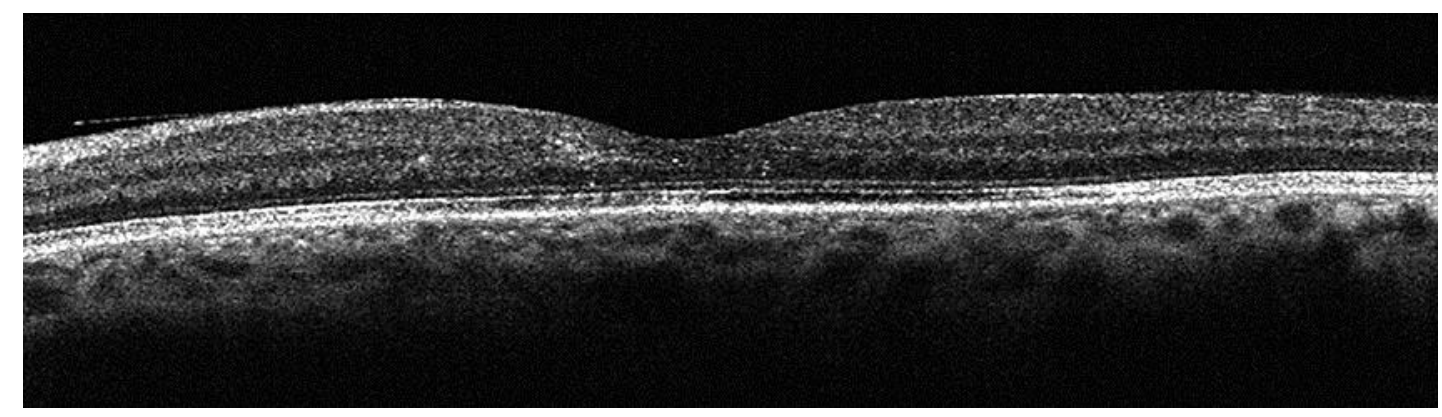

Fig. 3. OCT (iVue SD-OCT) of the OS 5 months after the last intravitreal ranibizumab injection, showing no recurrence of the retinal macroaneurysm. 